\title{
Overview on Multipattern and Multipolarization Antennas for Aerospace and Terrestrial Applications
}

\author{
Aixin Chen, ${ }^{1}$ Weiwei Jiang, ${ }^{1}$ Zhizhang Chen, ${ }^{2}$ and Jiaheng Wang ${ }^{1}$ \\ ${ }^{1}$ School of Electronic and Information Engineering, Beihang University, Beijing 100191, China \\ ${ }^{2}$ Department of Electrical and Computer Engineering, Dalhousie University, Halifax, NS, Canada B3J 2 X4 \\ Correspondence should be addressed to Aixin Chen; axchen@buaa.edu.cn
}

Received 17 February 2013; Accepted 12 March 2013

Academic Editor: Haiwen Liu

Copyright (c) 2013 Aixin Chen et al. This is an open access article distributed under the Creative Commons Attribution License, which permits unrestricted use, distribution, and reproduction in any medium, provided the original work is properly cited.

\begin{abstract}
In recent years, reconfigurable antennas, with the ability to radiate wave in more than one pattern and polarization, play a great role in modern telecommunication systems. Compared with conventional antennas, multipattern and multipolarization antennas have more advantages and better prospects. They can be used to improve system gain and security, satisfy system requirements, avoid noisy environment, and adapt to the environment flexibly. This paper discusses different patterns and polarizations of reconfigurable antennas according to current research work in this area. In the opinion of this paper, the radiation pattern states of antennas include beam direction, shape, and gain. The polarization states of antennas include horizontal/vertical linear, \pm slant $45^{\circ}$ linear, lefthand or right-hand circular polarized. Different multipattern and multipolarization antennas with various structures and working mechanisms are compared and discussed. Multipattern and multipolarization antennas have been well applied for aerospace and terrestrial applications, such as dynamic scenarios, adaptive beam scanning, and multiple-input-multiple-output (MIMO) systems.
\end{abstract}

\section{Introduction}

Generally, as we know, theconventional antennas only can work in one radiation pattern and polarization. When the environmental conditions or system requirements change, we need to reconfigure an antenna. It is inconvenient and costs too much. Reconfigurable antennas are a solution to solve this problem. They can change their radiation pattern and polarization timely to address complex system requirements by modifying their geometry and electrical behavior. Reconfigurable antennas can either increase the capabilities of wireless integrated information systems, expand their functionality, orwiden their bandwidths, with efficient spectrum and power utilization.

Compared to today's radio technology which depends on incompatible communication systems with inflexible hardware, the technology of reconfigurability will significantly reduce the hardware complexity, the number of components, and the cost. As described above, reconfigurable antennas promise to bring a host of benefits to future generation of wireless systems. Next-generation communication systems will rely upon reconfigurable antennas, such as wireless systems in dynamic scenarios (e.g., satellite/terminal tracking), adaptive beam scanning (e.g., radar/remote sensing), and MIMO systems (e.g., active management of channel correlation/diversity/interference). Among diversity of schemes at antenna level, multipattern and multipolarization antennas are important ones. They can be used to improve system gain and security, satisfy system requirement, avoid noisy environment, and adapt to the environment flexibly.

The concept of reconfigurable antenna was first presented in 1983 [1] and further investigation and realization were carried out and results were reported in [2]. In the recent years, reconfigurable antennas attracted more and more attention due to their capability of providing multipattern and multipolarization. One of the important applications is in aerospace and terrestrial wireless communication systems.

In the following sections, the classification of the multipattern and multipolarization antennas, the comparison between the different antennas with various structures and working mechanisms, the field of their application, and the vision and goal are to be discussed. 


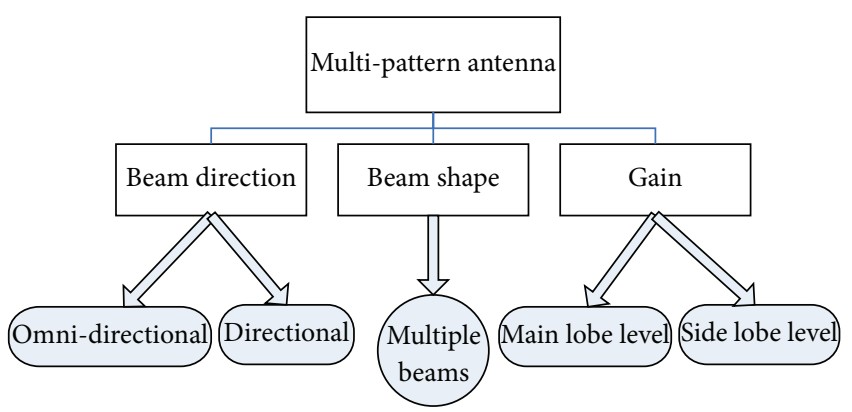

FIgURE 1: Classification of multipattern antennas.

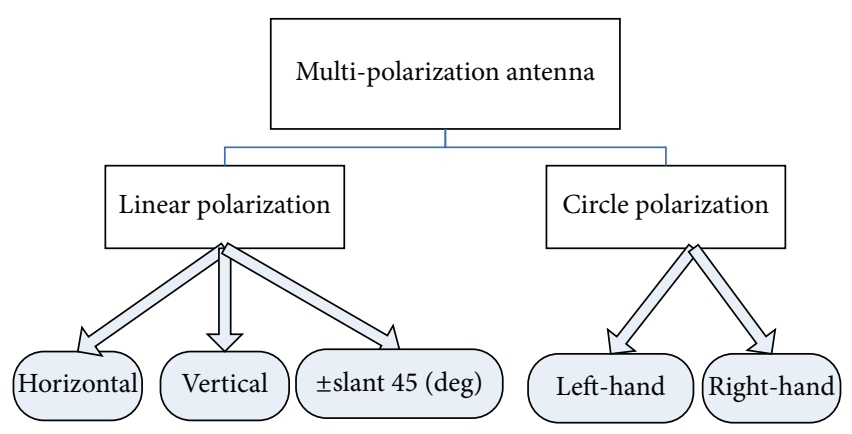

FIGURE 2: Classification of multipolarization antennas.

\section{Classification and Technologies of Reconfigurable Antennas}

In this paper, the reconfigurable antennas (mainly multipattern and multipolarization antennas here) can be classified into three categories: multipattern antennas, multipolarization antennas, and multipattern-multipolarization mixed reconfigurable antennas.

The multipattern antennas are divided into three major types achieved by changing the beam direction, beam shape, and gain, as indicated in Figure 1. The beam direction includes the omnidirectional and directional direction. Antennas which alter between omni-directional and directional radiation patterns [3-8] or vary the direction from one side to another side [9-17] are called the beam direction reconfigurable antennas. Beam shape reconfigurable antennas can be achieved by changing the number of beams (multiple beams) [18-21]. Finally, the gain reconfigurable antennas are able to be realized by changing the shape of beam's main lobe and side lobe [22-24].

The multipolarization antennas include linearly polarized antennas and circularly polarized antennas, as shown in Figure 2. A radiating structure that is able to change its polarization (horizontal, vertical, and radiations, and \pm slant $45^{\circ}$ ) is called linear polarization reconfigurable antennas [25-30]. Circular polarization reconfigurable antennas are achieved by varying polarization between left-hand circular and right-hand circular [31-39]. The antennas switching between the linear polarization and circular polarization are mixed polarization reconfigurable antennas [40-51].
The multipattern-multipolarization mixed reconfigurable antennas are the antennas which combine multipattern with multipolarization [52-61].

In order to realize various reconfigurable antennas, five major technologies are introduced.

(i) Electronically tuned reactance: alter the capacitors or inductors by varying the bias voltage. The common elements are varactor diodes and microelectromechanical-system- (MEM-S) tunable capacitors/ inductors.

(ii) Radio frequency (RF) electrical switches: by controlling the voltage, achieve the switches to be "on" state or the "off" state. PIN diodes, field effect transistor (FET) switches, and MEMS are popularly used.

(iii) Photoconductive switches: activate the semiconductor material (silicon, gallium arsenide) by controlling the laser light to realize the "on" state or the "off" state. It results in exciting electrons from the valence to the conduction band and thus creates a conductive connection.

(iv) Exotic materials: a static applied electric/magnetic field or voltage can change the relative material permittivity/permeability. The smart materials which are used in the substrate of the reconfigurable antennas include nematic liquid crystals, nonlinear materials, and ferroelectric films.

(v) Structural alteration: by altering the height, acreage, and shape of antenna, the physical structural is able to be modified. The altering structure is the antenna radiating parts.

The multipattern and multipolarization antennas are designed by implying the five major technologies to change surface current distribution, and the feeding network, the physical structure, the effective radiating aperture of antennas. The different patterns or polarizations correspond to different states caused by the technologies.

\section{Multipattern Antennas}

3.1. Beam Direction Reconfigurable Antennas. The conventional antennas can only work in the omni-directional or directional beam direction. The beam of omni-directional antenna homogeneously directs all the direction. The beam of directional antenna only directs in some range, but its radiated effect is better than that the omni-directional antenn. Consequently, we can choose the suitable type to meet the need of communication system. For example, in the case that the wireless access points distribute in different places and are close to the antenna, we should choose the omnidirectional antenna. On the contrary that the wireless access points are put together in one direction and long away from the antenna, the directional antenna is our choice. So we can see that the reconfigurable antenna with either omnidirectional or directional radiation pattern is very useful in wireless system. In addition, when the target is unique and always moves, for example, in the radar and terminal 


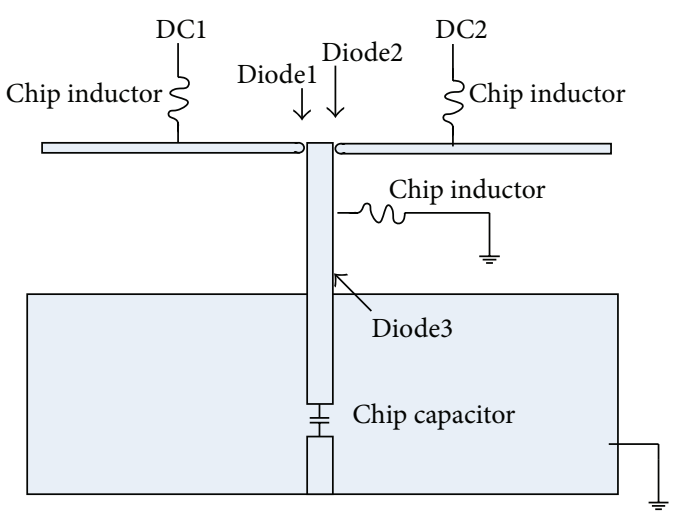

(a)

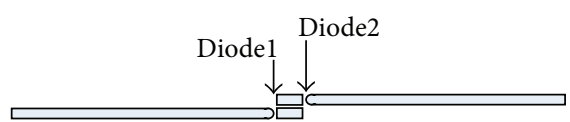

(b)

FIGURE 3: Radiation pattern reconfigurable antenna. (a) Side view. (b) Top view (redrawn after).

tracking system, the beam direction of antenna should change at the same time. The directional reconfigurable antenna fits it well. Next, three different examples of beam direction of reconfigurable antennas are described.

\subsubsection{Beam Direction Reconfigurable Antennas with Omnidi-} rectional and Directional Characteristics. This type of antennas can realize omni-directional and directional radiation. The antenna shown in Figure 3 is a simple radiation pattern reconfigurable antenna. The antenna is a combination of a monopole antenna and a dipole antenna with reflector [3]. Three switches are inserted to control the radiation pattern of antenna. The reconfigurable antenna can be operated as either a monopole antenna with an omnidirectional radiation pattern at the switches "on" state or a dipole antenna with reflector, which has directional radiation pattern at the switches "off" state. The antenna is compact and easy to control.

\subsubsection{Beam Direction Reconfigurable Antennas with Varied} Directional Characteristics. This is a type of complex radiation pattern reconfigurable antennas. A reconfigurable leakywave antenna capable of steering its radiation beam over a wide range is discussed in [9]. The antenna system is a microstrip composite right/left-hand (CRLH) leaky-wave antenna composed by 25 cascaded metamaterial unit cells, as shown in Figure 4. To achieve the CRLH behavior, insert an artificial series capacitance and a shunt inductance into a conventional microstrip line by means of an interdigital capacitor and a shorted stub, respectively. By tuning the bias voltage of varactor diodes $D_{\mathrm{S}}$ and $D_{\mathrm{SH}}$ separately, we can steer the radiation beam from $-55^{\circ}$ to $50^{\circ}$.

The fabricated antenna shown in Figure 5(a) is a planar $6 \times 6$ fully reconfigurable array operating at $5.7 \mathrm{GHz}$, capable of functioning both as a reconfigurable array lens and a reconfigurable reflectarray [10]. The array element consists of two varactor diode-loaded patches coupled by a varactor diode-loaded slot, as shown in Figure 5(b). In the lens mode, the antenna has a broadside directivity of $20.8 \mathrm{dBi}$ and a beam-scanning range of $50^{\circ}$ by $50^{\circ}$. The array as a reflectarray can achieve a directivity of $19.4 \mathrm{dBi}$ at broadside and a beamscanning range of $60^{\circ}$ by $30^{\circ}$. This array is able to demonstrate full $2 \mathrm{D}$ beamforming with low cost and is easy to fabricate.

3.2. Beam Shape Reconfigurable Antennas. The antennas which radiate multiple beams at the same time are called multibeam antennas. Multibeam antennas are able to both transmit signal in multiple directions at the same time with high gain and achieve the low side lobe by controlling the amplitude and phase of the feeds. To meet the different demand of communication system, we can change the number and shape of beams. Beam shape reconfigurable antennas are important and have been studied by many scientists.

A multifunctional reconfigurable antenna (MRA) capable of steering its radiation beam in the azimuth plane into one of 4 and 8 directions with variable beamwidth is presented in [20] (see Figure 6). The antenna is composed of a planar array of electrically small metallic square-shaped pixels which are interconnected by MEMS switches. By activating or deactivating the interconnecting MEMS switches, the geometry of the MRA dipole is changed. The antenna with optimum performance is able to apply for a wireless communication system.

3.3. Gain Reconfigurable Antennas. The beam makes up by main lobe and side lobe. In general, to improve the gain of antenna, we should increase the mainlobe level and lower the side lobe level as far as possible.

A flexible microstrip patch antenna incorporates a novel multilayer construction consisting of a liquid metal (eutectic gallium indium) encased in an elastomer [24]. The antenna is flexible and durable as its combined properties of the fluid and the elastomeric substrate, as shown in Figure 7(a). Injecting the metal into micro-fluidic channels provides a simple way to define the shape of the liquid, which is stabilized mechanically by a thin oxide skin that forms spontaneously on its surface. In Figure 7(b), a multilayer patch antenna is fabricated using specially designed serpentine channels that take advantage of the unique rheological property of the liquid metal alloy. And in Figure 7(c), by controlling the shape of antenna static, curving a low dielectric mandrel with a radius of $12.7 \mathrm{~mm}$, and curving around a similar mandrel with a radius of $25.4 \mathrm{~cm}$, separately, the antenna can realize three different values of gain. The flexibility antenna is well suited for conformal antenna applications.

\section{Multipolarization Antennas}

Comparing with classical antennas with single polarization, the multipolarization antennas offer advantages of reduction in installation space, low coupling effect, and low installation cost. Their intrinsic polarization diversity advantage is very useful in mitigating the multipath fading and increasing the 


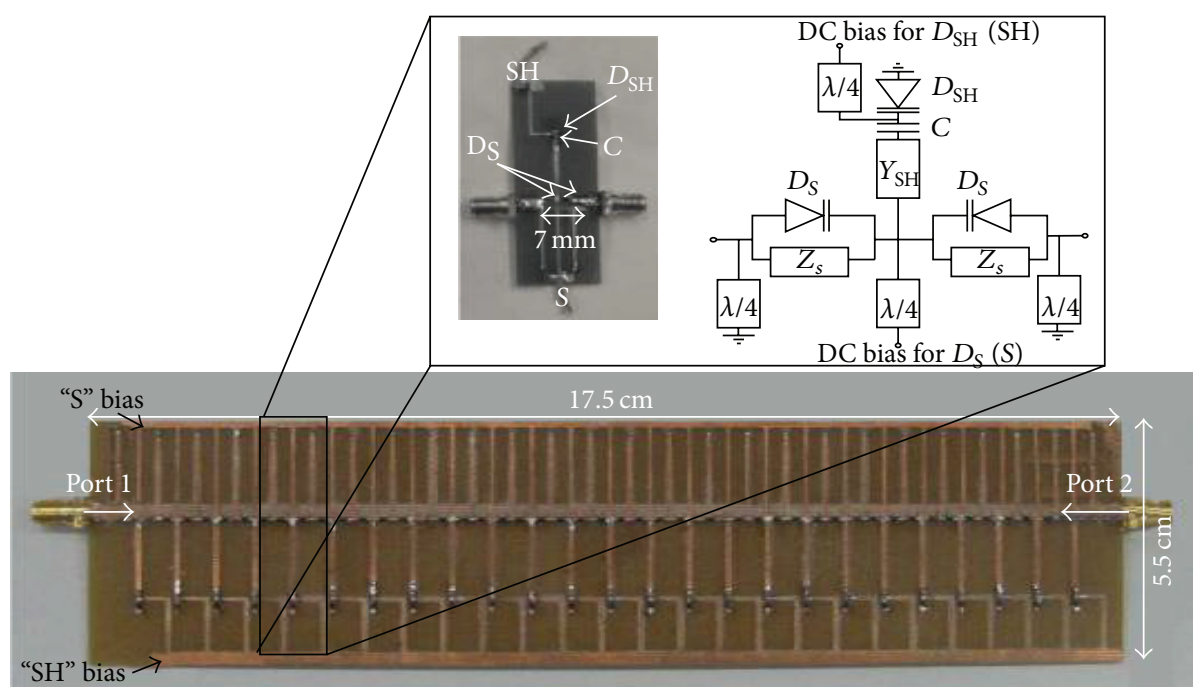

FIGURE 4: Two-port reconfigurable leaky-wave antenna and its tunable unit cell design (with permission from IEEE).

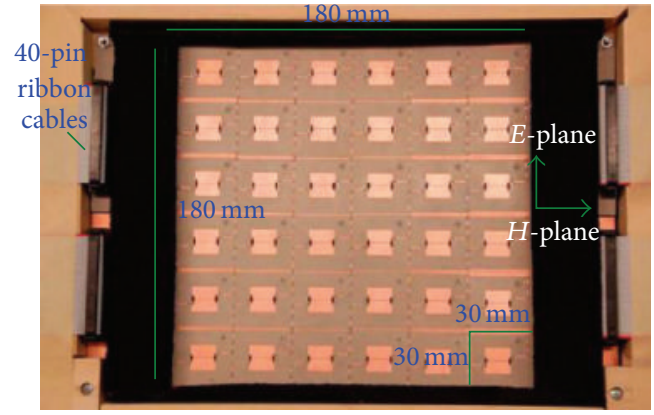

(a)

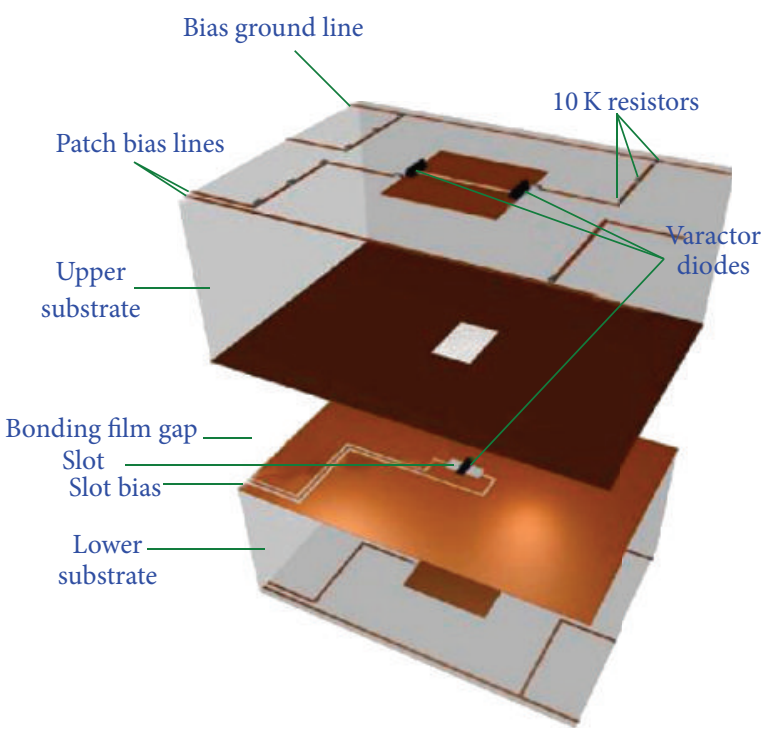

(b)

FIGURE 5: (a) Fabricated $6 \times 6$ planar reconfigurable array. (b) Array element and bias network design (vertically exaggerated) (with permission from IEEE).

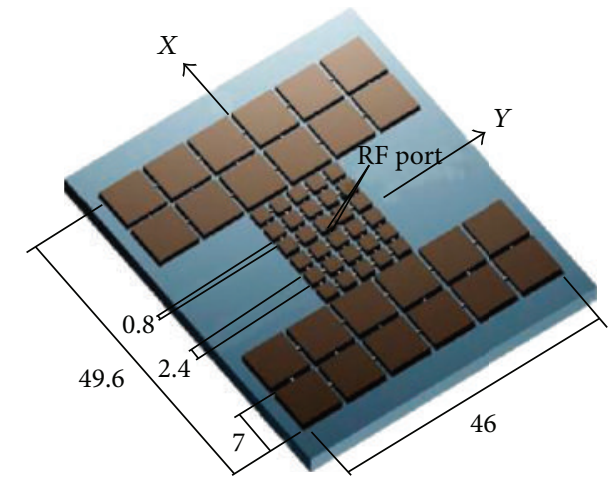

FIGURE 6: Multifunctional reconfigurable antenna (with permission from IEEE).

channel capacity, especially in polarization-varied environment. Such antennas can switch between linear polarization (LP) and circle polarization (CP), depending on the system requirements. The kinds of linear polarization include horizontal, vertical, and \pm slant $45^{\circ}$ polarization. The types of circular polarization are right-hand circular polarization (RHCP) and left-hand circular polarization (LHCP). In this section, three different polarization reconfigurable antennas to adjust the different propagation environment are presented as examples.

4.1. Linear Polarization Reconfigurable Antennas. A polarization reconfigurable slot antenna with compact feed is presented in [27]. Fed by dual modes of coplanar waveguide, dual orthogonal linear polarizations are excited in the slot and controlled by two PIN diodes. The antenna is composed by a rectangular slot, a coplanar waveguide (CPW), a capacitively coupled strip, and two PIN diodes. The rectangular slot 

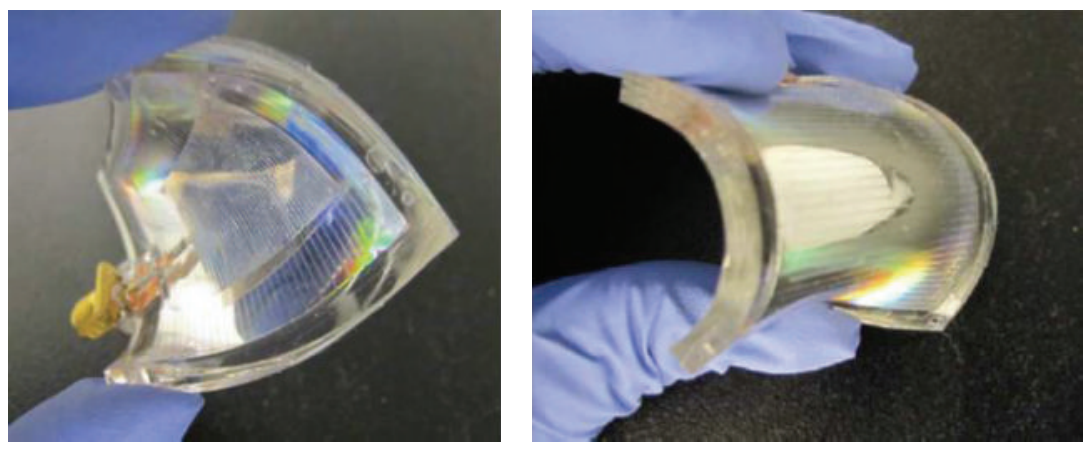

(a)
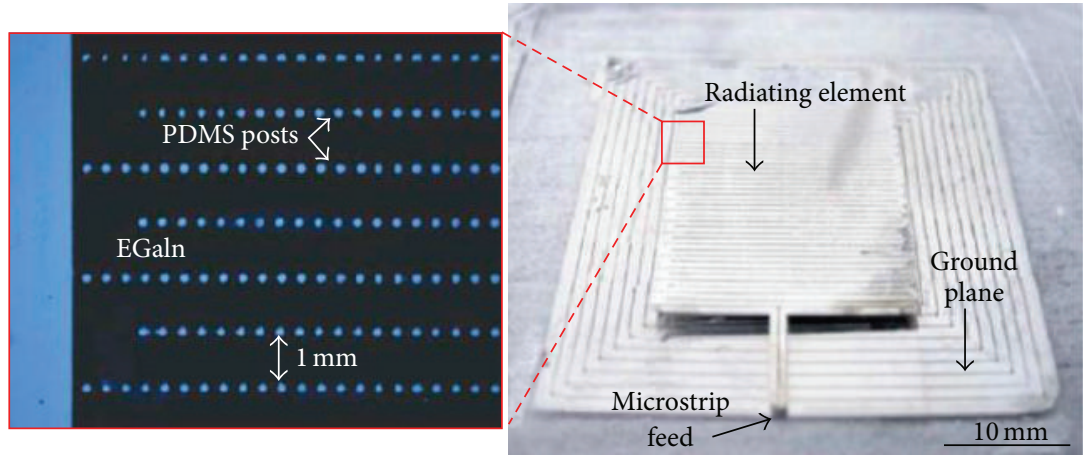

(b)

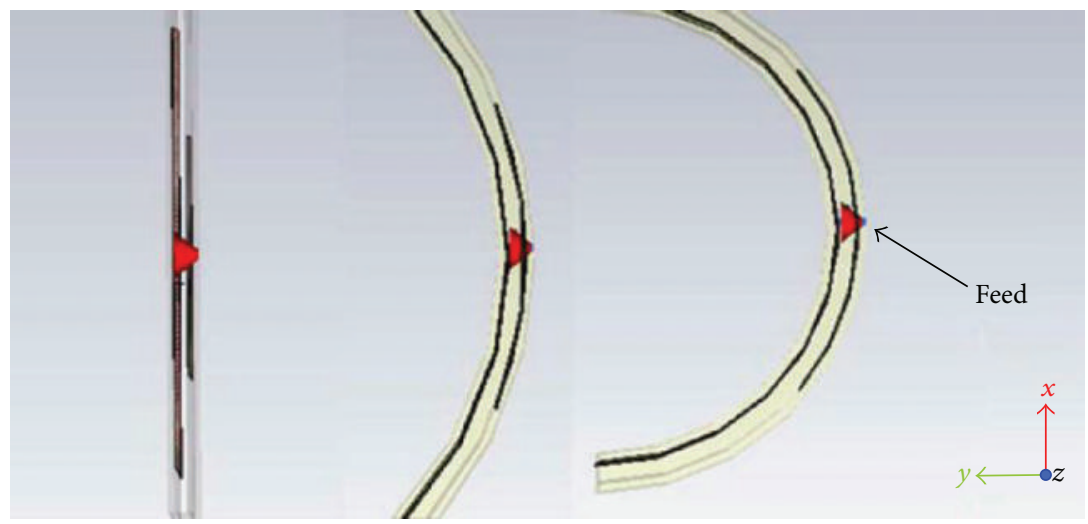

(c)

Figure 7: (a) Reconfigurable liquid metal alloy microstrip patch antenna. (b) The patch antenna and ground plane. (c) Cross-sectional view of the conformal configurations: (right) static, (middle) curved to a $25.4 \mathrm{~mm}$ radius, and (left) curved to a $12.7 \mathrm{~mm}$ radius (with permission from IEEE).

with the dimensions of $53 \times 50 \mathrm{~mm}^{2}$ serves as the radiation aperture, etched in the front side of FR4 $(\varepsilon r=4.4, \tan \delta=0.01)$. A switchable feed, including a C-shaped capacitively coupled strip at the back side and a CPW at the front side through, is controlled by two PIN diodes. The front side of fabricated antenna topology is shown in Figure 8(a). The back side of fabricated antenna structure is shown in Figure $8(\mathrm{~b})$. The bias circuit of the feed is shown in Figure 8(c). And the geometry of the slot antenna is shown in Figure 8(d). When PIN1 is "on" and PIN2 is "off," the antenna is fed through the C-shaped strip, which is capacitively coupled to the CPW.
As a result, the horizontal polarization of the slot is excited. When PIN1 is "off” and PIN2 is "on," the vertical polarization is excited by typical CPW feed structure. Dual orthogonal polarizations are achieved by dual orthogonal modes of CPW independently, making the feed structure compact.

4.2. Circular Polarization Reconfigurable Antennas. A circularly polarized reconfigurable microstrip array antenna with conical-beam radiation is shown in Figure 9 [39]. The array antenna structure consists of four L-shaped patch elements 


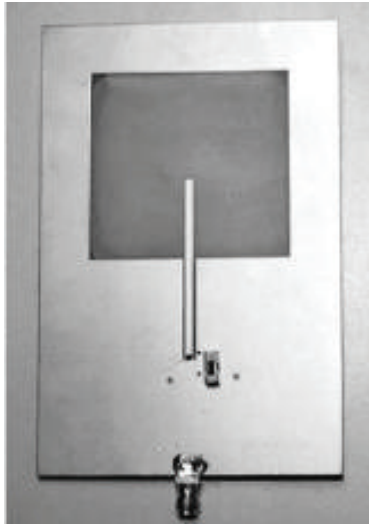

(a)

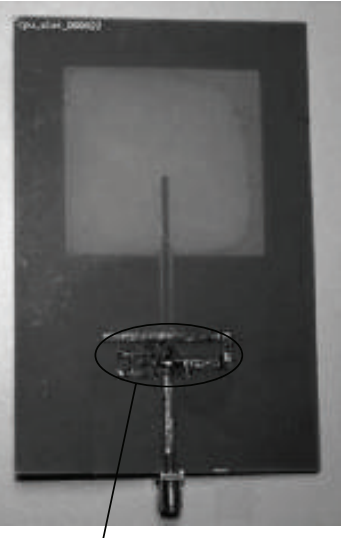

(b)

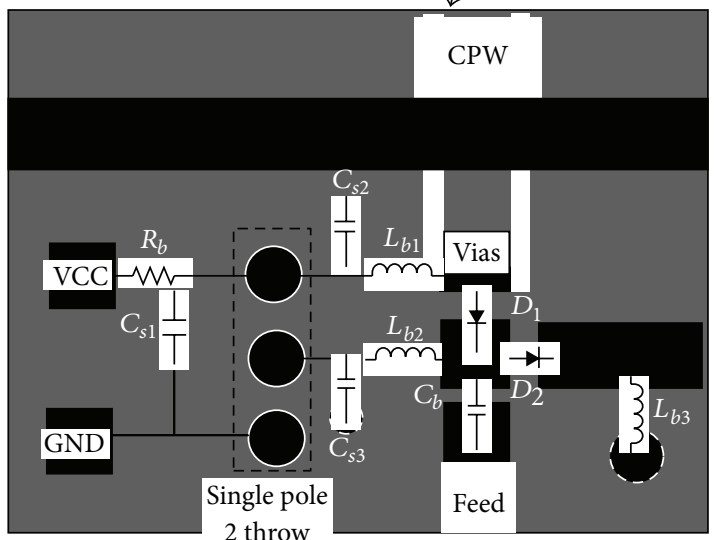

switch
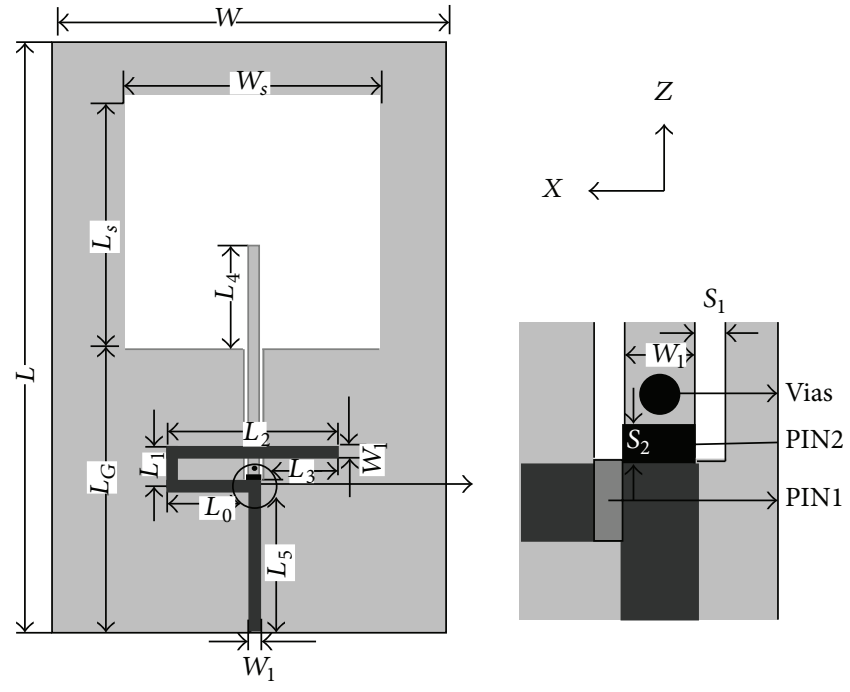

(d)

Figure 8: (a) Front side of fabricated polarization reconfigurable antenna. (b) Back side. (c) Bias circuit of the feed. (d) Geometric structure (with permission from John Wiley and Sons).
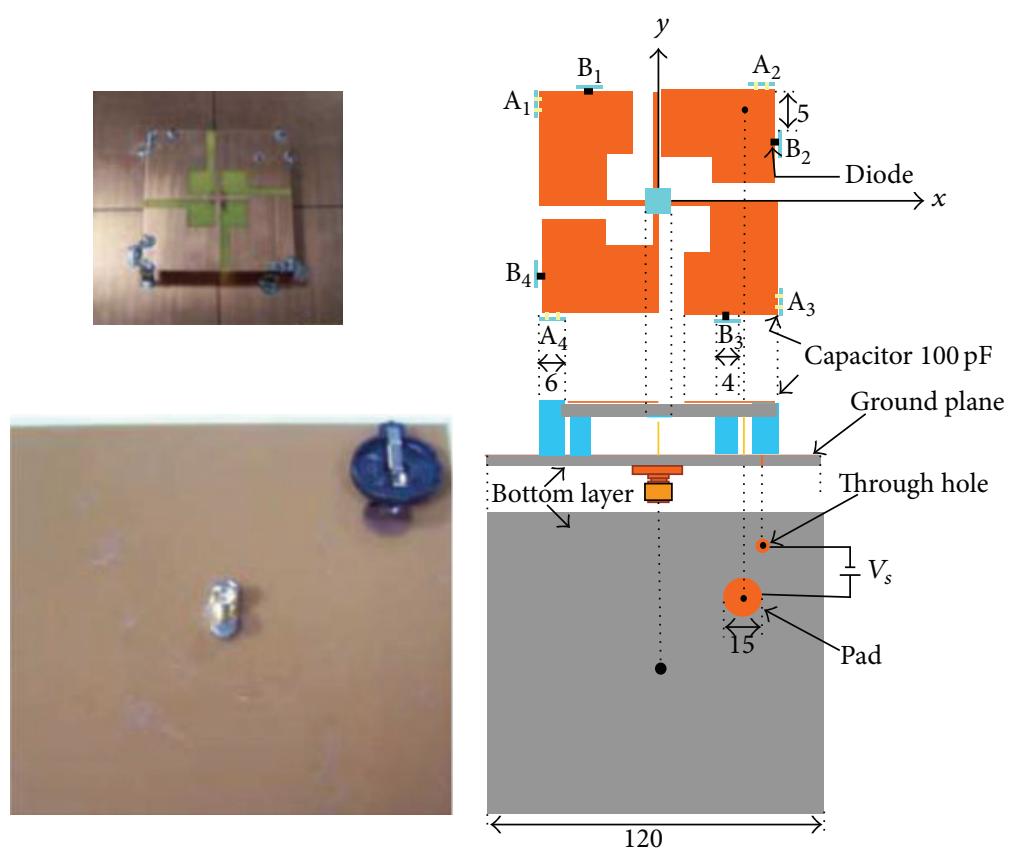

FIGURE 9: Layout of a reconfigurable CP microstrip array and the finished prototype (with permission from IEEE). 


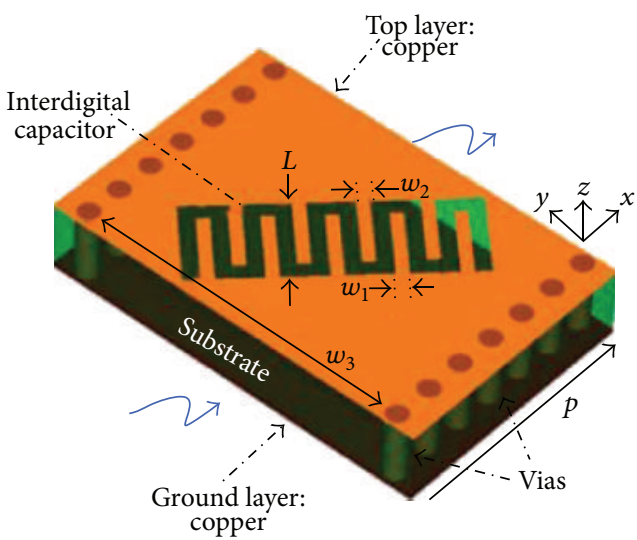

(a)

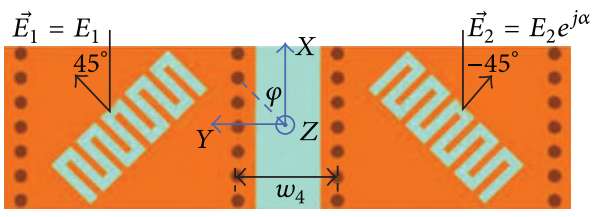

(c)

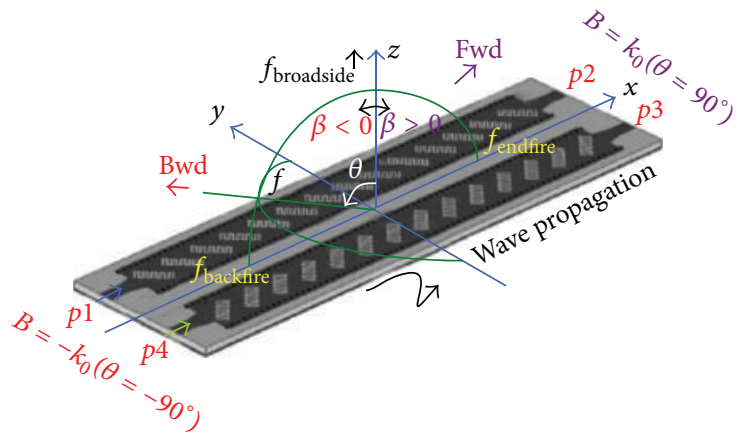

(b)

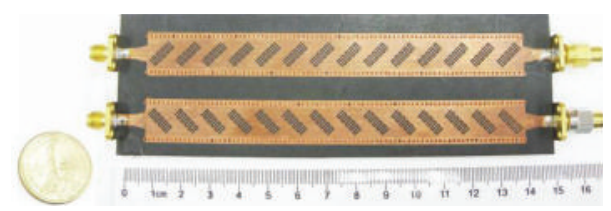

(d)

Figure 10: Polarization reconfigurable CRLH-SIW antenna. (a) Single radiating element. (b) Two-element unit cell of the whole structure. (c) Overall LW antenna prototype. (d) fabricated antenna (with permission from IEEE).

arranged in a square-ring formation. Each patch is shorted to the ground plane through conducting walls. With a toploaded monopole feed, two orthogonal resonant modes, loop mode and monopole mode, can be excited simultaneously. When the monopole mode and the loop mode are properly coupled, the microstrip array can generate a $\mathrm{CP}$ radiation. By controlling the frequency, the antenna can switch between LHCP and RHCP. In addition the array has the characteristic of omnidirectional radiation and conical beam.

4.3. Mixed Polarization Reconfigurable Antennas. A composite right/left-handed (CRLH) leaky-wave (LW) antenna with flexible polarization is presented in [41]. The leaky transmission line (TL) is a planar passive circuit built using the substrate integrated waveguide technology. It consists of two symmetrical waveguide lines loaded with series interdigital capacitors which radiate orthogonal 45 linearly polarized waves, as shown in Figure 10. The configuration of single radiating element is shown in Figure 10(a). Two-element unit cell of the whole structure is shown in Figure 10(b). The overall LW antenna prototype is shown in Figure 10(c). Photograph of the fabricated LW antennas is shown in Figure 10(d). The antenna is able to generate arbitrary different polarization states by changing the way of excitation, including LP and CP. This leaky TL is fabricated by the standard printedcircuit board process. Two broadband couplers are also designed and fabricated for the specified excitation purpose. Six different polarization states, including four LP cases (horizontal, vertical, and \pm slant $45^{\circ}$ ) and two CP ones (left hand and right hand), can be realized. The LW structure shows some desirable merits, such as the simplicity in design, low-cost fabrication, and beam-steering and polarizationflexible capabilities, providing a high degree of flexibility for the real application.

\section{Multipattern-Multipolarization Mixed Reconfigurable Antennas}

This type of antennas realizes multipattern and multipolarization characteristics by using one reconfigurable antenna. A novel reconfigurable microstrip antenna with radiation pattern selectivity and polarization diversity is discussed in [57]. As shown in Figure 11(a), A four-way power divider made by three Wilkinson power dividers and interconnected with switches (switch A and switch B) is designed to feed-fourrectangular-radiating-patcheantenna. By controlling the state of the switches, the antenna characteristics can be changed into two modes. When switch A is closed and switch B is open, the four rectangular radiating patches are excited by four sources with equal amplitude and phase. A metamaterial antenna with conical beam and linear polarization is achieved. When switch A is open and switch B is closed, four sources with equal amplitude but 90-phase difference for each adjacent output lead to a wideband antenna with broadside beam and circular polarization. The photographs of measurement setup and fabricated antenna are shown in Figure 11(b). This single-port antenna is useful for terrestrial land mobile or other wireless applications. 


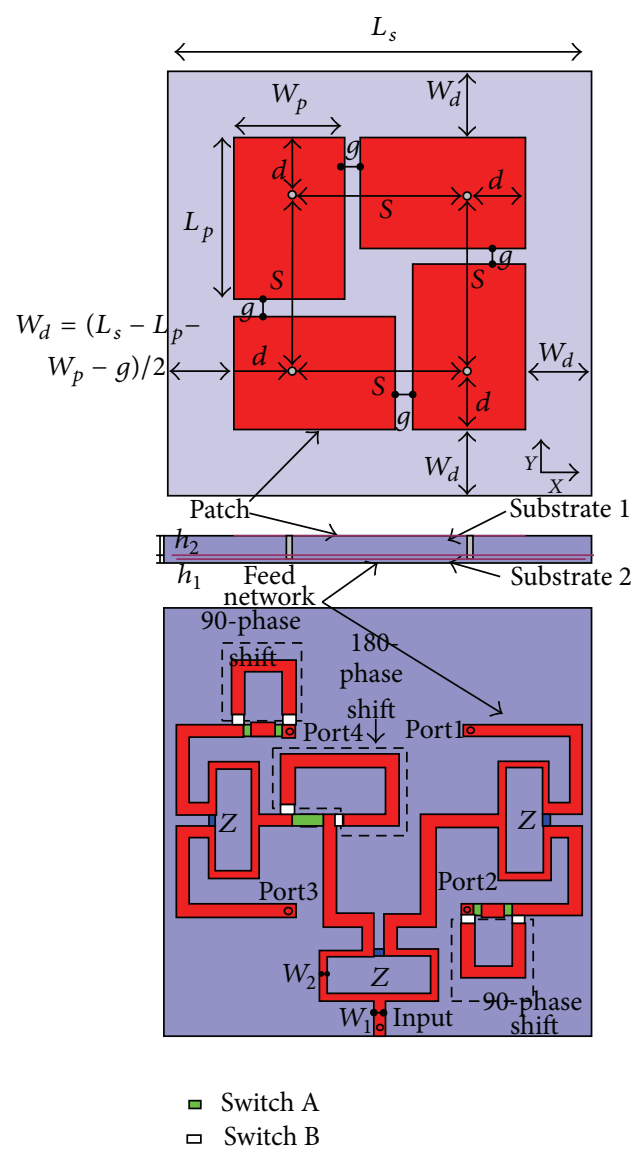

(a)
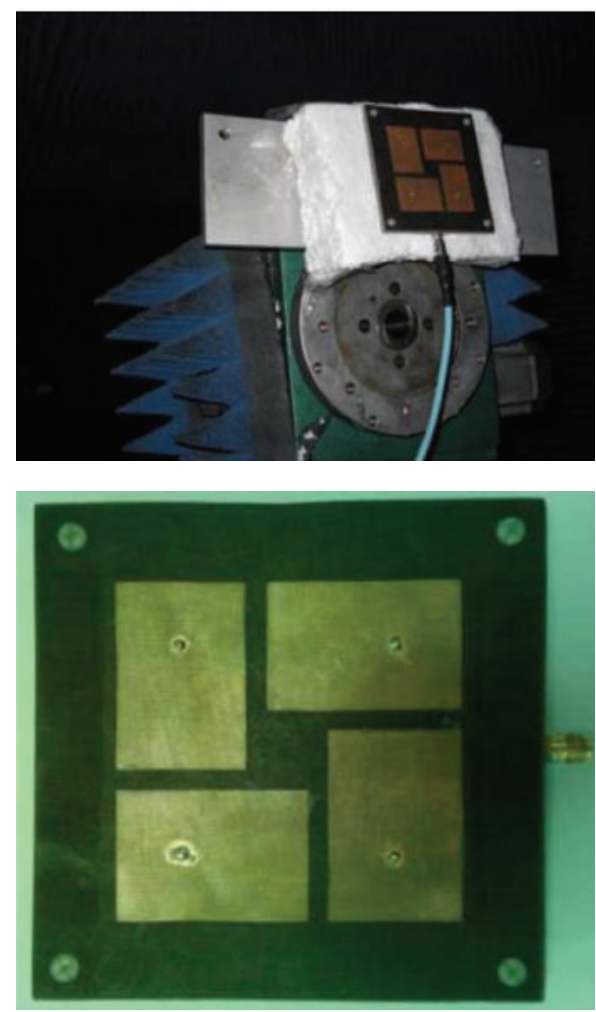

(b)

FIGURE 11: (a) The pattern and polarization reconfigurable microstrip antenna. (top) Top view. (middle) Side view. (bottom) Bottom view. (b) Measurement setup photograph and the fabricated antenna (with permission from IEEE).

\section{Comparison between Multipattern and Multipolarization Antennas}

As shown in Figure 12, multipattern and multipolarization antennas described above can be divided into two types according to the method of feed: connected feed or spatial feed. The classification criteria are whether the feed of the antenna is connected to the radiator or not. The reconfigurable reflectarray antennas and lens antennas, which are classified as spatial feed, generally feed by horn antennas or others, as described in $[10,13,15,25,26,29,61]$. Most antennas presented in this paper have a connected feed. Compared with the connected-feed antennas, the spatialfeed reconfigurable reflectarray antennas and lens antennas have the advantages of the gain of a reflector antenna changeable with the flexibility of an array, feed losses and layout problems eliminated through the use of a spatial feed, and system amenable to closed-loop control. However, they have limitations of scanning range, feed blockage, and profile.

The reconfigurable antennas with a connected feed include planer antennas and nonplanar antennas. The nonplanar reconfigurable antennas in the form of waveguide antenna and cubic antenna are discussed in $[19,36]$, respectively. They are able to avoid outside interference and radiation loss due to their simple closed structure. Nevertheless, paralleling with planar reconfigurable antenna, they are more difficult to integrate with the circuit because of nonplanar structure and are less popular in reconfigurable area due to inflexible structure.

The planar reconfigurable antennas fed by coaxial or coplanar waveguide are mainly made up of microstrip antennas $[7-9,33-35,37-39,42-46,48-52,57-60]$, substrate integrated waveguide (SIW) antennas [11, 12, 40, 41], and monopole or dipole antennas $[3-5,16,17,20,53,55]$. The microstrip antennas are widely used in reconfigurable antennas with the advantages of small size, light weight, low profile, and ease of integration. The SIW antennas have both the microstrip antenna's advantages of low profile and being easy to integrate and the waveguide antenna's merits of low radiation loss and high efficiency. But, compared to the microstrip-reconfigurable antenna, they are more difficult to process and have lower flexibility. The monopole or dipole antennas have flexible structure, but their ordinary is gain lower than SIW antennas. 


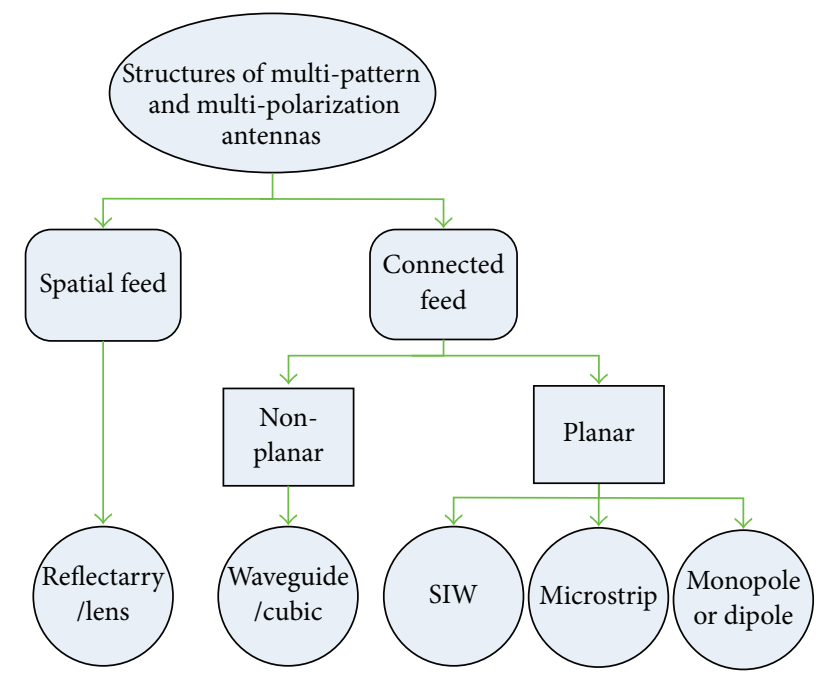

FIGURE 12: The different structures of multipattern and multipolarization antennas.

\section{Applications}

The reconfigurable antennas with multipattern and multipolarization have been used in both aerospace and terrestrial wireless communication to improve spectrum efficiency, such as wireless systems in dynamic scenarios, adaptive beam scanning, and MIMO systems. In dynamic scenarios, it is necessary to reconfigure the antenna radiation pattern to maintain high data rate, serve a new coverage zone, and limit fading in rainy areas at all possible frequency bands of operation. The dynamic scenarios including satellite and terminal tracking are discussed in [26, 50, 62-64]. In the adaptive beam scanning system, the antenna should automatically change its radiation beam direction corresponding to the various propagation environments or moving target, such as in the system of radar and remote sensing [6568]. A MIMO system employs multiple antennas at both the transmitter and receiver front ends. Pattern and polarization reconfigurable antennas are widely studied and adopted in MIMO systems for their intrinsic pattern and polarization diversity advantage in mitigating the multipath fading and increasing the channel capacity, especially in pattern and polarization varied environments. The MIMO system with reconfigurable antennas is able to actively manage channel correlation, diversity, and interference $[9,17,18,27,31,59,69$, $70]$.

\section{Vision and Goal}

Even though the research on the multipattern and multipolarization antennas has got some achievements, we still have a long way to go. Until now, the reconfigurable antennas which have been studied and researched are not smart enough that they are not completely multifunctional and software controlled with machine. In addition, the antennas still only play a role of the transducers. A very interesting goal is that we can create field programmable antenna system which enjoys the same flexibility as other field-programmable devices. In the field-programmable antenna system, the reconfigurable antennas can detect changes in their RF environment and react accordingly. If such system is realized, the antennas are evolved from simple transducers to advanced wave processors, along with the advantages of the utilization of radiation pattern selectivity and polarization diversity to transmit over already "busy" frequencies. And the reconfigurable antennas will play more a important role in aerospace and terrestrial applications.

\section{Conclusion}

This paper presents an overview on the multipattern and multipolarization antennas. The concepts, characteristics, and typical antennas of radiation patterns and polarizations are introduced. A comparison between different multipattern and multipolarization antennas with different structures and working mechanisms are also discussed. The reconfigurable antennas can be well applied to dynamic scenarios, adaptive beam scanning, and MIMO systems. The goal in the future work is to realize the field programmable antenna system to evolve antennas from simple transducers to advanced wave processors.

\section{Acknowledgments}

This work was supported in part by the National Science Foundation of China and NSAF under their joint Grant no. 11076031 .

\section{References}

[1] D. H. Schaubet, F. G. Farrar, S. T. Hayes et al., "Frequencyagile polarization diverse microstrip antennas and frequency scanned arrays," U.S. Patent 4,367,474, Jan. 1983.

[2] C. G. Christodoulou, Y. Tawk, S. A. Lane, and S. R. Erwin, "Reconfigurable antennas for wireless and space applications," Proceedings of the IEEE, vol. 100, no. 7, pp. 2250-2261, 2012.

[3] W. S. Kang, J. A. Park, and Y. J. Yoon, "Simple reconfigurable antenna with radiation pattern," Electronics Letters, vol. 44, no. 3, pp. 182-183, 2008.

[4] M. I. Lai, T. Y. Wu, J. C. Hsieh, C. H. Wang, and S. K. Jeng, "Design of reconfigurable antennas based on an L-shaped slot and PIN diodes for compact wireless devices," IET Microwaves, Antennas and Propagation, vol. 3, no. 1, pp. 47-54, 2009.

[5] L. G. Maloratsky, "Switched directional/omnidirectional antenna module for amplitude monopulse systems," IEEE Antennas and Propagation Magazine, vol. 51, no. 5, pp. 90-102, 2009.

[6] F. Peruani and A. Maiti, "Modeling broadcasting using omnidirectional and directional antenna in delay tolerant networks as an epidemic dynamics," IEEE Journal on Selected Areas in Communications, vol. 28, no. 4, pp. 524-531, 2010.

[7] M. Ding, R. Jin, J. Geng, X. Guo, and J. Chen, "A high-gain dual-band directional/omnidirectional reconfigurable antenna for WLAN systems," International Journal of RF and Microwave Computer-Aided Engineering, vol. 18, no. 3, pp. 225-232, 2008.

[8] M. Donelli, R. Azaro, L. Fimognari, and A. Massa, "A planar electronically reconfigurable wi-fi band antenna based on a 
parasitic microstrip structure," IEEE Antennas and Wireless Propagation Letters, vol. 6, pp. 623-626, 2007.

[9] D. Piazza, M. D’Amico, and K. R. Dandekar, "Performance improvement of a wideband MIMO system by using two-port RLWA," IEEE Antennas and Wireless Propagation Letters, vol. 8, pp. 830-834, 2009.

[10] J. Y. Lau and S. V. Hum, "A planar reconfigurable aperture with lens and reflectarray modes of operation," IEEE Transactions on Microwave Theory and Techniques, vol. 58, no. 12, pp. 3547-3555, 2010.

[11] A. Suntives and S. V. Hum, "A fixed-frequency beam-steerable half-mode substrate integrated waveguide leaky-wave antenna," IEEE Transactions on Antennas and Propagation, vol. 60, no. 5, pp. 2540-2544, 2012.

[12] A. Suntives and S. V. Hum, "An electronically tunable halfmode substrate integrated waveguide leaky-wave antenna," in Proceedings of the 5th European Conference on Antennas and Propagation (EUCAP '11), pp. 3670-3674, April 2011.

[13] C. Liu and S. V. Hum, "An electronically tunable single-layer reflectarray antenna element with improved bandwidth," IEEE Antennas and Wireless Propagation Letters, vol. 9, pp. 1241-1244, 2010.

[14] L. Boccia, I. Russo, G. Amendola, and G. Di Massa, "Multilayer antenna-filter antenna for beam-steering transmit-array applications," IEEE Transactions on Microwave Theory and Techniques, vol. 60, no. 7, pp. 2287-2300, 2012.

[15] W. Hu, M. Y. Ismail, R. Cahill et al., "Liquid-crystal-based reflectarray antenna with electronically switchable monopulse patterns," Electronics Letters, vol. 43, no. 14, pp. 744-745, 2007.

[16] C. J. Panagamuwa, A. Chauraya, and J. C. Vardaxoglou, "Frequency and beam reconfigurable antenna using photoconducting switches," IEEE Transactions on Antennas and Propagation, vol. 54, no. 2, pp. 449-454, 2006.

[17] D. Piazza, N. J. Kirsch, A. Forenza, R. W. Heath, and K. R. Dandekar, "Design and evaluation of a reconfigurable antenna array for MIMO systems," IEEE Transactions on Antennas and Propagation, vol. 56, no. 3, pp. 869-881, 2008.

[18] Z. Li, Z. Du, and K. Gong, "Compact reconfigurable antenna array for adaptive MIMO systems," IEEE Antennas and Wireless Propagation Letters, vol. 8, pp. 1317-1320, 2009.

[19] J. Sarrazin, Y. Mahé, S. Avrillon, and S. Toutain, "Pattern reconfigurable cubic antenna," IEEE Transactions on Antennas and Propagation, vol. 57, no. 2, pp. 310-317, 2009.

[20] H. Eslami, C. P. Sukumar, D. Rodrigo et al., "Reduced overhead training for multi reconfigurable antennas with beam-tilting capability," IEEE Transactions on Wireless Communications, vol. 9, no. 12, pp. 3810-3821, 2010.

[21] Y. Yang, X. Zhao, and T. Wang, "Design of arbitrarily controlled multi-beam antennas via optical transformation," Journal of Infrared, Millimeter, and Terahertz Waves, vol. 30, no. 4, pp. 337348, 2009.

[22] A.-H. Tsai, L.-C. Wang, J.-H. Huang, and R.-B. Hwang, "Stable subchannel allocation for OFDMA femtocells with switched multi-beam directional antennas," in Proceedings of the IEEE Global Telecommunications Conference (GLOBECOM '11), pp. 16, December 2011.

[23] G. Krieger, N. Gebert, and A. Moreira, "Multidimensional waveform encoding: a new digital beamforming technique for synthetic aperture radar remote sensing," IEEE Transactions on Geoscience and Remote Sensing, vol. 46, no. 1, pp. 31-46, 2008.
[24] G. J. Hayes, J.-H. So, A. Qusba, M. D. Dickey, and G. Lazzi, "Flexible liquid metal alloy (EGaIn) microstrip patch antenna," IEEE Transactions on Antennas and Propagation, vol. 60, no. 5, pp. 2151-2156, 2012.

[25] M. F. Jamlos, T. A. Rahman, and M. R. Kamarudin, "The effects of air stacked on reconfigurable quadratic slots antenna for WiMAX and 4G applications," Microwave and Optical Technology Letters, vol. 54, no. 9, pp. 2139-2144, 2012.

[26] T. Takano, K. Miura, M. Natori et al., "Deployable antenna with 10-m maximum diameter for space use," IEEE Transactions on Antennas and Propagation, vol. 52, no. 1, pp. 2-11, 2004.

[27] Y. Li, Z. Zhang, J. Zheng, and Z. Feng, "Channel capacity study of polarization reconfigurable slot antenna for indoor MIMO system," Microwave and Optical Technology Letters, vol. 53, no. 6, pp. 1209-1213, 2011.

[28] B. Q. Wu and K. M. Luk, "The design of wideband reconfigurable antenna with four polarizations," in Proceedings of the 39th European Microwave Conference (EuMC '09), pp. 759-762, September 2009.

[29] A. Clemente, L. Dussopt, R. Sauleau et al., "1-bit reconfigurable unit cell based on PIN diodes for transmit-array applications in X-band," IEEE Transactions on Antennas and Propagation, vol. 60, no. 5, pp. 2260-2269, 2012.

[30] G. Wang, R. Bairavasubramanian, B. Pan, and J. Papapolymerou, "Radiofrequency MEMS-enabled polarisation-reconfigurable antenna arrays on multilayer liquid crystal polymer," IET Microwave Antenna and Propagation, vol. 5, no. 13, pp. 1594-1599, 2011.

[31] A. Grau, J. Romeu, M. J. Lee, S. Blanch, L. Jofre, and F. de Flaviis, "A dual-Linearly-polarized MEMS-reconfigurable antenna for narrowband MIMO communication systems," IEEE Transactions on Antennas and Propagation, vol. 58, no. 1, pp. 417, 2010.

[32] P. Seongmin and S. Imseob, "A miniaturized switchable circularly polarized patch antenna controlled by a single diode operation," Microwave and Optical Technology Letters, vol. 54, no. 10, pp. 2375-2378, 2012.

[33] K. F. Tong and J. Huang, "New proximity coupled feeding method for reconfigurable circularly polarized microstrip ring antennas," IEEE Transactions on Antennas and Propagation, vol. 56, no. 7, pp. 1860-1866, 2008.

[34] W. S. Yoon, J. W. Baik, H. S. Lee, S. Pyo, S. M. Han, and Y. S. Kim, "A reconfigurable circularly polarized microstrip antenna with a slotted ground plane," IEEE Antennas and Wireless Propagation Letters, vol. 9, pp. 1161-1164, 2010.

[35] P. Seongmin and S. Youngje, "A circular polarized microstrip antenna with an arrow-shaped slotted ground," Microwave and Optical Technology Letters, vol. 54, no. 1, pp. 271-273, 2012.

[36] J. A. Ruiz-Cruz, M. M. Fahmi, S. A. Fouladi, and R. R. Mansour, "Waveguide antenna feeders with integrated reconfigurable dual circular polarization," IEEE Transactions on Microwave Theory and Techniques, vol. 59, no. 12, pp. 3365-3374, 2011.

[37] S. H. Hsu and K. Chang, "A novel reconfigurable microstrip antenna with switchable circular polarization," IEEE Antennas and Wireless Propagation Letters, vol. 6, pp. 160-162, 2007.

[38] A. Khaleghi and M. Kamyab, "Reconfigurable single port antenna with circular polarization diversity," IEEE Transactions on Antennas and Propagation, vol. 57, no. 2, pp. 555-559, 2009.

[39] J. S. Row and M. C. Chan, "Reconfigurable circularly-polarized patch antenna with conical beam," IEEE Transactions on Antennas and Propagation, vol. 58, no. 8, pp. 2753-2757, 2010. 
[40] Y. J. Cheng, W. Hong, and K. Wu, "Millimeter-wave half mode substrate integrated waveguide frequency scanning antenna with quadri-polarization," IEEE Transactions on Antennas and Propagation, vol. 58, no. 6, pp. 1848-1855, 2010.

[41] Y. Dong and T. Itoh, "Millimeter-Wave half mode substrate integrated waveguide frequency scanning antenna with quadripolarization," IEEE Transactions on Antennas and Propagation, vol. 60, no. 2, pp. 760-771, 2012.

[42] X.-X. Yang, B.-C. Shao, F. Yang et al., "A polarization reconfigurable patch antenna with loop slots on the ground plane," IEEE Antennas and Wireless Propagation Letters, vol. 11, pp. 69-72, 2012.

[43] Y. F. Wu, C. H. Wu, D. Y. Lai, and F. C. Chen, "A reconfigurable quadri-polarization diversity aperture-coupled patch antenna," IEEE Transactions on Antennas and Propagation, vol. 55, no. 3, pp. 1009-1012, 2007.

[44] R. H. Chen and J. S. Row, "Single-fed microstrip patch antenna with switchable polarization," IEEE Transactions on Antennas and Propagation, vol. 56, no. 4, pp. 922-926, 2008.

[45] O. H. Karabey, S. Bildik, and S. Strunck, "Continuously polarisation reconfigurable antenna element by using liquid crystal based tunable coupled line," Electronics Letters, vol. 48, no. 3, pp. 141-143, 2012.

[46] B. Kim, B. Pan, S. Nikolaou, Y. S. Kim, J. Papapolymerou, and M. M. Tentzeris, "A novel single-feed circular microstrip antenna with reconfigurable polarization capability," IEEE Transactions on Antennas and Propagation, vol. 56, no. 3, pp. 630-638, 2008.

[47] H. Emami, N. Sarkhosh, and E. R. L. Lara, "Reconfigurable photonic feed for sinuous antenna," Journal of Light Wave Technology, vol. 30, no. 16, pp. 2725-2732, 2012.

[48] P. Y. Qin, A. R. Weily, Y. J. Guo, and C. H. Liang, "Polarization reconfigurable U-slot patch antenna," IEEE Transactions on Antennas and Propagation, vol. 58, no. 10, pp. 3383-3388, 2010.

[49] M. S. Nishamol, V. P. Sarin, D. Tony et al., "An electronically reconfigurable microstrip antenna with switchable slots for polarization diversity," IEEE Transactions on Antennas and Propagation, vol. 59, no. 9, pp. 3424-3427, 2011.

[50] J. H. Lim, G. T. Back, and T. Y. Yun, "Polarization-diversity cross-shaped patch antenna for satellite-DMB systems," ETRI Journal, vol. 32, no. 2, pp. 312-318, 2010.

[51] X. Yuan, Z. Li, D. Rodrigo et al., "A parasitic layer-based reconfigurable antenna design by multi-objective optimization," IEEE Transactions on Antennas and Propagation, vol. 60, no. 6, pp. 2690-2701, 2012.

[52] X.-S. Yang, B.-Z. Wang, S.-H. Yeung et al., "Circularly polarized reconfigurable crossed-vagi patch antenna," IEEE Antennas and Propagation Magazine, vol. 53, no. 5, pp. 65-80, 2011.

[53] Y. Dong and T. Itoh, "Planar ultra-wideband antennas in kuand k-band for pattern or polarization diversity applications," IEEE Transactions on Antennas and Propagation, vol. 60, no. 6, pp. 2886-2895, 2012.

[54] B. Poussot, J. M. Laheurte, L. Cirio, and O. Picon, "Diversity gain measurements of a reconfigurable antenna with switchable polarization," Microwave and Optical Technology Letters, vol. 49, no. 12, pp. 3154-3158, 2007.

[55] B. Poussot, J. M. Laheurte, L. Cirio, O. Picon, D. Delcroix, and L. Dussopt, "Diversity measurements of a reconfigurable antenna with switched polarizations and patterns," IEEE Transactions on Antennas and Propagation, vol. 56, no. 1, pp. 31-38, 2008.

[56] P. Daniele and D. Michele, "Pattern and polarization reconfigurable CRLH leaky wave antenna," in Proceedings of the 4th
European Conference on Antennas and Propagation (EuCAP '10), pp. 1-5, April 2010.

[57] W. Cao, B. Zhang, A. Liu et al., "A reconfigurable microstrip antenna with radiation pattern selectivity and polarization diversity," IEEE Antennas and Wireless Propagation Letters, vol. 11, pp. 453-456, 2012.

[58] W. Chen, J. Sun, and Z. Feng, "A novel compact reconfigurable polarization and pattern antenna," Microwave and Optical Technology Letters, vol. 49, no. 11, pp. 2802-2805, 2007.

[59] D. Piazza, P. Mookiah, M. D’Amico, and K. R. Dandekar, "Experimental analysis of pattern and polarization reconfigurable circular patch antennas for MIMO systems," IEEE Transactions on Vehicular Technology, vol. 59, no. 5, pp. 23522362, 2010.

[60] W. L. Liu, T. R. Chen, S. H. Chen, and J. S. Row, "Reconfigurable microstrip antenna with pattern and polarisation diversities," Electronics Letters, vol. 43, no. 2, pp. 77-78, 2007.

[61] A. G. Besoli and F. D. Flaviis, "A multifunctional reconfigurable pixeled antenna using mems technology on printed circuit board," IEEE Transactions on Antennas and Propagation, vol. 59, no. 12, pp. 4413-4424, 2011.

[62] M. Ali, A. T. M. Sayem, and V. K. Kunda, "A reconfigurable stacked microstrip patch antenna for satellite and terrestrial links," IEEE Transactions on Vehicular Technology, vol. 56, no. 2, pp. 426-435, 2007.

[63] M. D. van de Burgwal, K. C. Rovers, KC. H. Blom et al., "Mobile satellite reception with a virtual satellite dish based on a reconfigurable multi-processor architecture," Microprocessors and Microsystems, vol. 35, no. 8, pp. 716-728, 2011.

[64] J. A. Lee, S. B. Byun, J. H. Lim, and T. Y. Yun, "Reconfigurable antenna for wideband code division multiple access and korean satellite digital multimedia broadcasting controlled by PINdiodes," Microwave and Optical Technology Letters, vol. 49, no. 6, pp. 1334-1337, 2007.

[65] M. Alshershby and J. Q. Lin, "Reconfigurable plasma antenna produced in air by laser-induced filaments: passive radar application," in Proceedings of the International Conference on Optoelectronics and Microelectronics (ICOM '12), pp. 364-371, August 2012.

[66] N. Romano, G. Prisco, and F. Soldovieri, "Design of a reconfigurable antenna for ground penetrating radar applications," Progress in Electromagnetics Research, vol. 94, pp. 1-18, 2009.

[67] F. Soldovieri and N. Romano, "The mutual interaction between the reconfigurable transmitting and receiving antennas in ground penetrating radar surveys," Journal of Electromagnetic Waves and Applications, vol. 23, no. 14-15, pp. 1919-1928, 2009.

[68] M. F. Jamlos, O. A. Aziz, T. A. Rahman et al., "A reconfigurable radial line slot array (RLSA) antenna for beam shape and broadside application," Journal of Electromagnetic Waves and Applications, vol. 24, no. 8-9, pp. 1171-1182, 2010.

[69] P. A. Martin, P. J. Smith, and R. Murch, "Improving space-time code performance in slow fading channels using reconfigurable antennas," IEEE Communications Letters, vol. 16, no. 4, pp. 494497, 2012

[70] F. Fazel, A. Grau, H. Jafarkhani, and F. de Flaviis, "Spacetime-state block coded MIMO communication systems using reconfigurable antennas," IEEE Transactions on Wireless Communications, vol. 8, no. 12, pp. 6019-6029, 2009. 

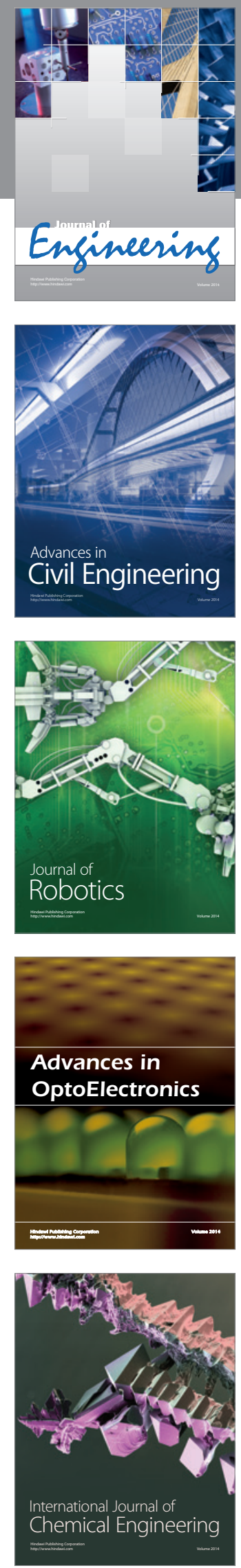

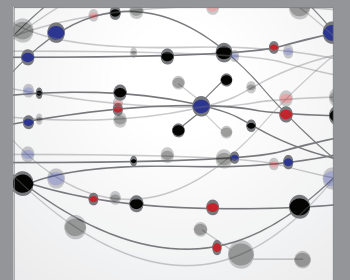

The Scientific World Journal
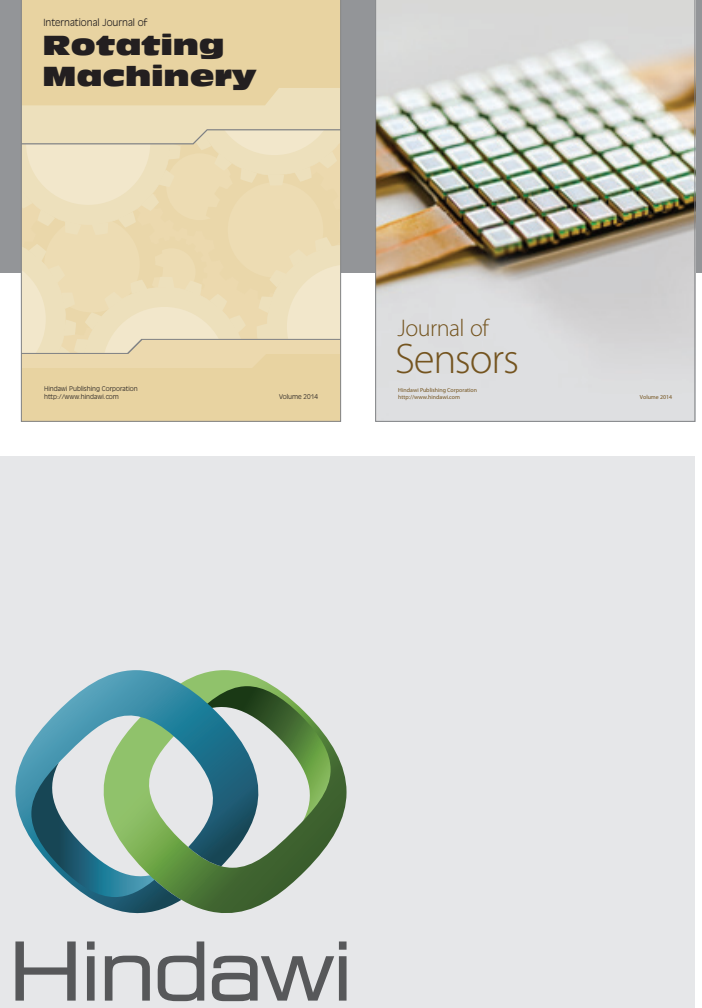

Submit your manuscripts at http://www.hindawi.com
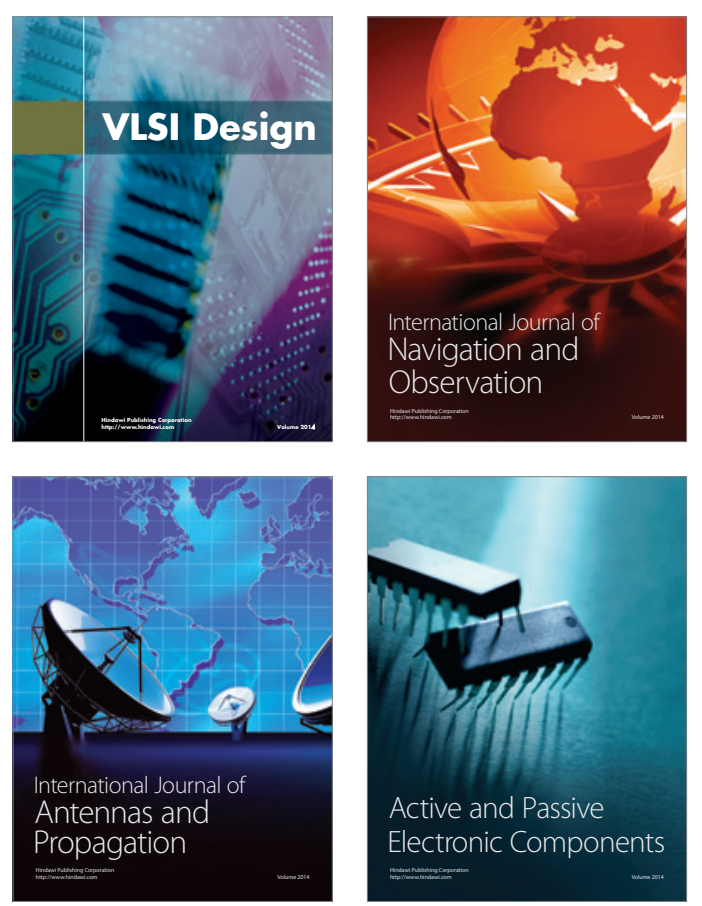
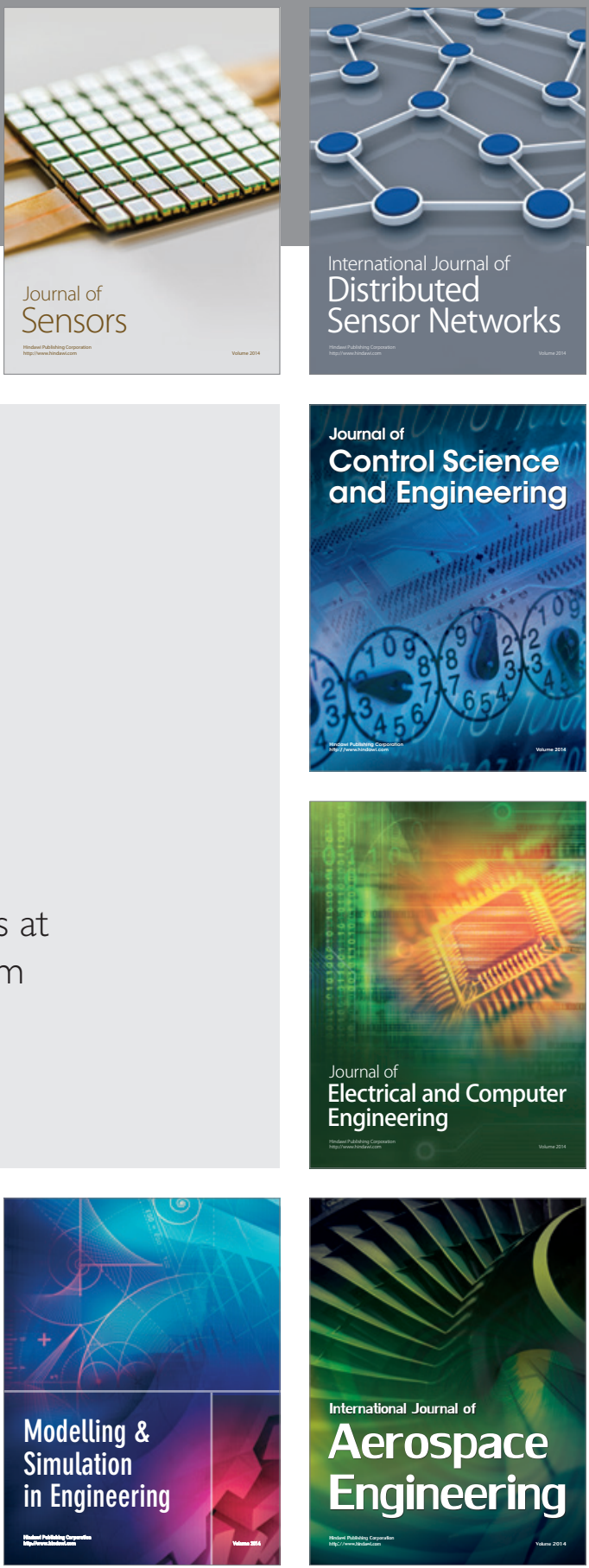

Journal of

Control Science

and Engineering
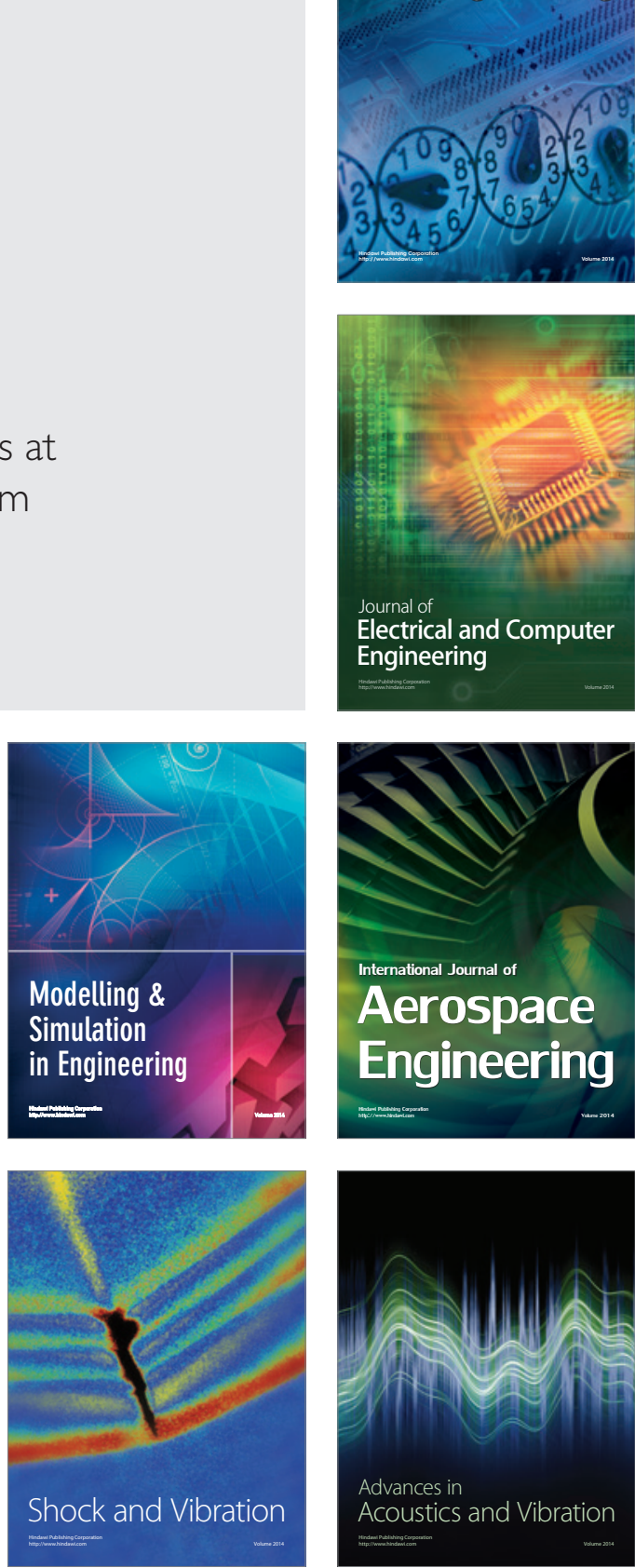